\title{
Induction of Oxidative Stress: A Possible Mechanism for the Arsenic Induced Catastrophes in Male Wistar Rats
}

\author{
John Olabode Fatoki ${ }^{1}$ Jelili Abiodun Badmus ${ }^{1} \quad$ Comfort Oluwatoyin Fatoki ${ }^{2}$ \\ Adeniran Sanmi Adekunle $^{1} \quad$ Gbadebo Emmanuel Adeleke ${ }^{1 *} \quad$ Samuel Abiodun Kehinde ${ }^{3}$ \\ 1.Department of Biochemistry, Faculty of Basic Medical Sciences, Ladoke Akintola University of Technology, \\ Ogbomoso, Nigeria \\ 2.Department Microbiology, Faculty of Basic and Applied Sciences, Osun State University, Osogbo, Nigeria \\ 3.Department of Biochemistry, College of Biosciences, Federal University of Agricultural, Abeokuta, Nigeria \\ *Corresponding author: Gbadebo Emmanuel Adeleke: geadeleke@lautech.edu.ng
}

\begin{abstract}
Arsenic is an environmental pollutant and its contamination in the drinking water is considered as a serious worldwide environmental health threat. The present study investigated the effects of arsenic exposure on antioxidant parameters and p53 expression in male albino rats. The animals $(n=45)$ were exposed to arsenic $(100$ ppm, $150 \mathrm{ppm}$ and $200 \mathrm{ppm})$ for 4, 8 and 12 weeks as sodium arsenate in drinking water. Control animals $(\mathrm{n}=15)$ received distilled water for the same period. Hepatic superoxide dismutase (SOD), catalase, glutathione peroxidase $(\mathrm{GPx})$, reduced glutathione $(\mathrm{GSH})$, lipid peroxidation and total protein were evaluated spectrophotometrically. Expression of p53 was also detected by histochemical staining. Before the commencement of arsenic exposure, five animals were sacrificed to obtain baseline data. ANOVA followed by Tukey's test was used to analyse the results with $\mathrm{p}<0.05$ considered significant. Significant decrement in hepatic activities of SOD, catalase and GPx as well as hepatic concentration of GSH and total protein concentration characterized exposure to all the dose regimens of inorganic arsenic at all the time interval. Corroboratively, significant elevation was observed in malondialdehyde (MDA). The expression of p53 decreased in the groups that were exposed to arsenic as compared to the control animals. The findings from the present study suggests excessive generation of free radicals and reduction in p53 expression in arsenic - induced hepatotoxicity.
\end{abstract}

Keywords: Arsenic, Toxicity, Antioxidants, Lipid peroxidation

DOI: $10.7176 /$ ALST/75-04

Publication date:June $30^{\text {th }} 2019$

\section{Introduction}

Arsenic is a toxic metalloids, it exists in $+5,+3,0$, and -3 oxidation states. It also exists in both organic and inorganic form in the environment. Arsenic in these four oxidation states is widely and ubiquitously distributed in the environment as a results of natural and anthropogenic activities in the environment. The +5 (arsenate) and +3 (arsenite) oxidation states are the most common forms of the natural occurring arsenic in the environment (Obinaju, 2009; Mateos et al., 2010, satyapal et al., 2018). The major cause of arsenic toxicity in human is due to exposure to contaminated drinking water from natural geological sources as most countries of the world have their drinking water contaminated with arsenic (Gebel, 2000; Matschullat, 2000; Zaw \& Emett, 2002). Apart from drinking contaminated water, other form of exposure includes but not limited to; inhalation, absorption through the skin. Arsenicals may also enter food chain from agricultural products (Ratnaike, 2003). The major absorption site of arsenic in human is the ileum by an electrogenic process involving a proton gradient (Ratnaike \& Barbour 2000), and are deposited in the skin, lungs, kidney, liver and heart. Lower amount of arsenic has however been reported have been observed in the muscles and neuronal tissues (Klaassen, 1996). Meanwhile, Flora et al. (2007) also reported that prolong exposure to arsenic for two to four weeks can also cause its incorporation into the nails and hair by binding to sulfhydryl groups of keratin.

Arsenic inactivates approximately 200 enzymes involved in many important metabolic reactions such as cellular energy metabolism and DNA replication and repair with concomitant induction of plethora of diseases by oxidative stress, altered DNA methylation, altered DNA repair, mitochondrial damage, uncontrolled cell proliferation leading to promotion of tumourigenesis. Arsenicals can also substituted for phosphate in high energy compound such as ATP with concomitant consequences on energy metabolism of the cell (Ratnaike, 2003; Butt \& Rehman, 2011).

The overall effectiveness of the electron transport chain notwithstanding, a small amount of electrons leak out of the respiratory chain and can therefore partially reduce oxygen to form reactive oxygen species (ROS) such as $\mathrm{O}_{2}$., $\mathrm{H}_{2} \mathrm{O}_{2}$ and ${ }^{-} \mathrm{OH}$ (Finsterer \& Ohnsorge, 2013). These ROS are generated in normal cellular metabolism and signal transduction (Zhang et al., 2014). They can however cause oxidative damage to cellular macromolecules such as nucleic acids, proteins and lipids (Pace et al., 2017). Innate antioxidants such as SOD, catalase and glutathione peroxidase are the first line of defense against ROS effects. An amplified mitochondrial production of ROS and/or reduced intrinsic antioxidant capacity leads to an increased oxidative stress and are linked with a multitude of downstream effects as well as disease initiation and progression (Moskovitz et al., 
2002). Similarly, previous studies have shown that p53, a tumor suppressor gene is an important transcription factor that regulates apoptosis, cell cycle progression and cellular senescence (Feridooni et al., 2011; Ma et al., 2013). It is a well-established inducer of apoptosis, and it shows the most common genetic mutation found in cancers (Demirovic et al., 2014). Functionally, p53 therefore plays an important role in the maintenance of genomic stability (Rolland et al., 2007).

Arsenic and its mechanisms of action has been the subject of reviews and symposia and its mechanism of action therefore is not yet completely understood (Flora et al., 2007). Although Ghosh et al. (2011) proposed free radical mediated theory to explain arsenic - induced catastrophes. In the present study however, we investigated the effects of low, intermediate and high doses of sodium arsenate exposure on hepatic redox status and the expression of p53 protein over a duration of 4,8 and 12 weeks, aimed at proposing a possible mechanism for arsenic - induced hepatotoxicity.

\section{Materials and Methods}

\subsection{Chemicals}

All chemicals used in this study were of the purest grade available and were obtained from the British Drug House (BDH) Chemicals Limited, Poole, England and Sigma-Aldrich, Missouri, U. S. A.

\subsection{Experimental animals}

Sixty five (65) male wistar rats obtained from the Animal house of the Faculty of Basic Medical Sciences, Ladoke Akintola University of Technology, Ogbomoso, with body weight ranging from 120 - $140 \mathrm{~g}$ were used for this study. They were housed in plastic cages and were acclimatized for 14 days before the commencement of arsenic exposure. They were allowed free access to standard rat pellet diet purchased from Vita Feeds Nigeria Limited and drinking water ad libitum. Animals were maintained at temperature of $29 \pm 2{ }^{\circ} \mathrm{C}$ and regular lightdark cycle (06:00-18:00h) throughout the study.

\subsection{Study design}

At the commencement of the study, five (5) animals were sacrificed to obtain the baseline data. The remaining sixty (60) animals were randomly assigned into twelve (12) groups of five (5) animals each. Nine (9) groups were exposed to $100 \mathrm{ppm}, 150 \mathrm{ppm}$ and $200 \mathrm{ppm}$ inorganic arsenic as disodium arsenate $\left(\mathrm{Na}_{2} \mathrm{HAsO}_{4}\right)$ in their drinking water for four (4), eight (8) and twelve (12) weeks. The remaining three (3) groups served as control rats for each of the time intervals and received distilled water over the same period of time.

\subsection{Collection of organ}

The rats were fasted overnight at the end of arsenic exposure. The liver was quickly excised from the animals under light ether anesthesia. The liver was washed in ice cold $1.15 \%$ potassium chloride solution to remove blood stain and dried. A section of the liver was homogenized in phosphate buffer at $\mathrm{pH} 7.4$ and centrifuged at $5000 \mathrm{rpm}$ for $10 \mathrm{~min}$ and was used for biochemical assays, while the other section of the liver was stored in $10 \%$ formalin and used for immuno - histochemical for p53 protein.

\subsection{Biochemical assays}

Determination of hepatic superoxide dismutase activity. Superoxide dismutase (SOD) was evaluated using Fortress diagnostic kit which employed the method described by Arthur (1985). Briefly, xanthine and xanthine oxidase are used to generate free radicals, which in turn react with 2-(4-iodophenyl)-3-(4-nitrophenol)-5-phenyl tetrazolium chloride (I.N.T) to form a red formazan dye. One unit of SOD is that which causes a $50 \%$ inhibition of the rate of reduction of I.N.T under the conditions of the assay.

Determination of hepatic catalase activity. Hepatic catalase activity was assayed by the method of Sinha (1972).

Determination of hepatic glutathione peroxidase activity. Hepatic glutathione peroxidase (GPx) activity was evaluated using the method of Rotruck et al. (1957).

Reduced glutathione determination. The method described by Beutler et al. (1963) was employed in evaluating the level of reduced glutathione in the liver homogenate.

Determination of hepatic MDA concentration. Lipid peroxidation was evaluated by measuring thiobarbituric reactive oxygen species (TBARS) in form of MDA using the method described by Varshney and Kale (1990).

Total protein determination. Hepatic total protein concentration was determined according to the method of Biuret (1949).

Immuno-histochemical assay. The immunochemical staining of liver for expressions of p53 was done according to the method of Chakravarthi et al. (2010), with slight modification. Slides were observed under a binocular microscope. Cells with specific brown colour in the cytoplasm, cell membrane or nuclei, depending on the antigenic sites, were considered positive. 
2.6 Statistical analysis

Results are expressed as mean \pm SEM. One-way analysis of variance (ANOVA) followed by Tukey's test was used to analyze the results with $\mathrm{p}<0.05$ considered significant.

\section{Results}

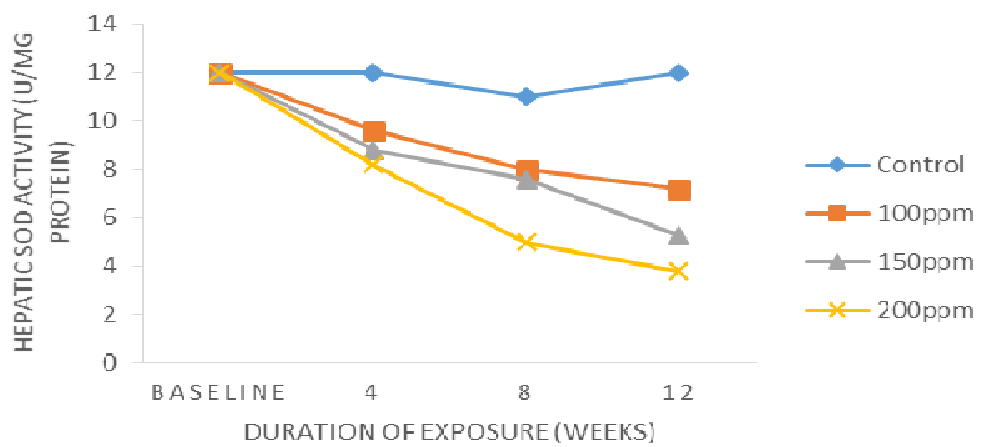

Fig 1: Hepatic SOD activity in rats exposed to different doses of inorganic arsenic.

Exposure to 100, 150 and $200 \mathrm{ppm}$ inorganic arsenic resulted in significant $(p<0.05)$ reduction of hepatic superoxide dismutase activity (Fig. 1). The reduction in the activity of the enzyme was however time and dose dependent. At four weeks, exposure of the animals to $100 \mathrm{ppm}$ produced $20 \%$ reduction in the activity of SOD in the liver however, when the dose and duration of exposure was increased to $200 \mathrm{ppm}$ and 12 weeks respectively, the effect produced by the arsenic compound became $68 \%$.

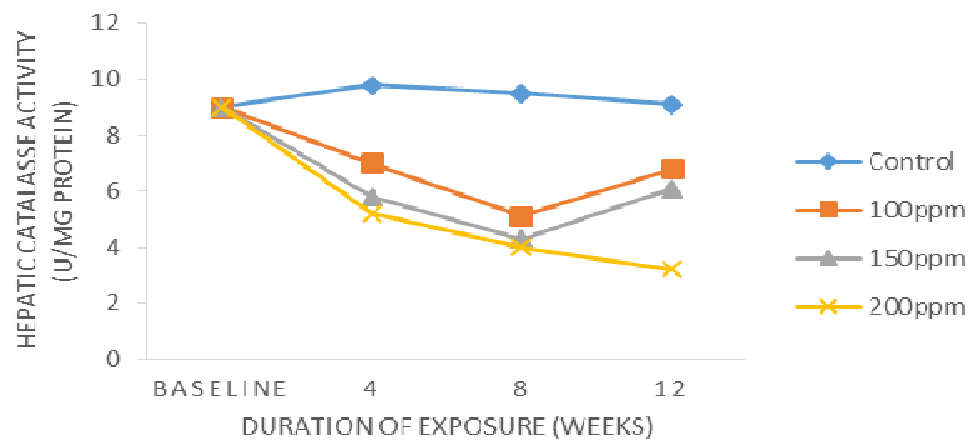

Fig. 2: Hepatic Catalase Activity in rats exposed to different doses of inorganic arsenic.

The mean hepatic catalase activity of the animals exposed to different doses of inorganic arsenic are depicted in fig. 2. Inorganic arsenic induced a significant $(p<0.05)$ reduction in the activity of catalase in the liver. At the doses of 100 and $150 \mathrm{ppm}$, the reduction was time dependent up till 8 weeks. On the other hand, at $200 \mathrm{ppm}$, the reduction in catalase activity was time dependent up till 12 weeks. At 4, 8 and 12 weeks, the effect of arsenic compound on the hepatic catalase activity was dose dependent. Exposure to 100 ppm arsenic for 4 and 8 weeks caused about $26 \%$ reduction in the activity of the enzyme, while exposure to 200 ppm inorganic arsenic caused about 3 - fold reduction in the activity of hepatic catalase.

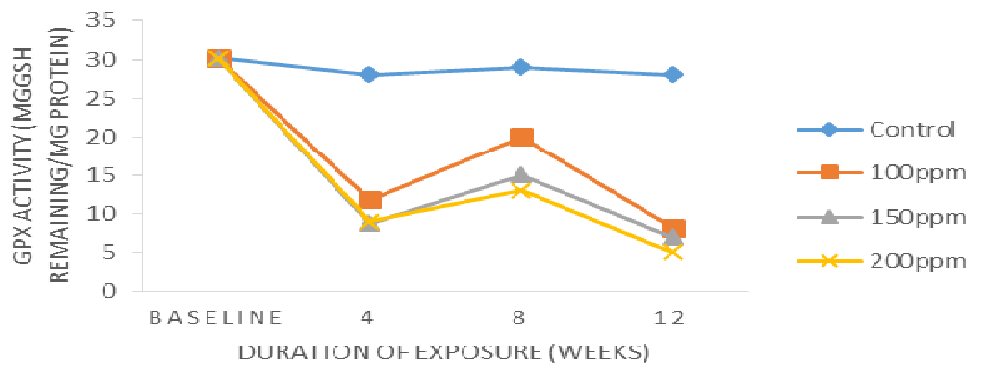

Fig. 3: Hepatic GPx Activity in rats exposed to different doses of inorganic arsenic.

The hepatic GPx activity as affected by exposure to sodium arsenate is depicted in fig. 3 . When compared with the control, the hepatic GPx activity was significantly $(p<0.05)$ decreased following exposure to 100,150 
and 200 ppm sodium arsenate for 4, 8 and 12 weeks. This observed decrement is most significant and dose dependent at 8 weeks. When compared with the control, 100, 150 and 200 ppm sodium arsenate caused a 31, 48 and $55 \%$ decrease in the activity of the antioxidant enzyme respectively. Similarly, the response to the three doses of inorganic arsenate was also a dose dependent down - regulation of the activity of GPx in the hepatocytes.

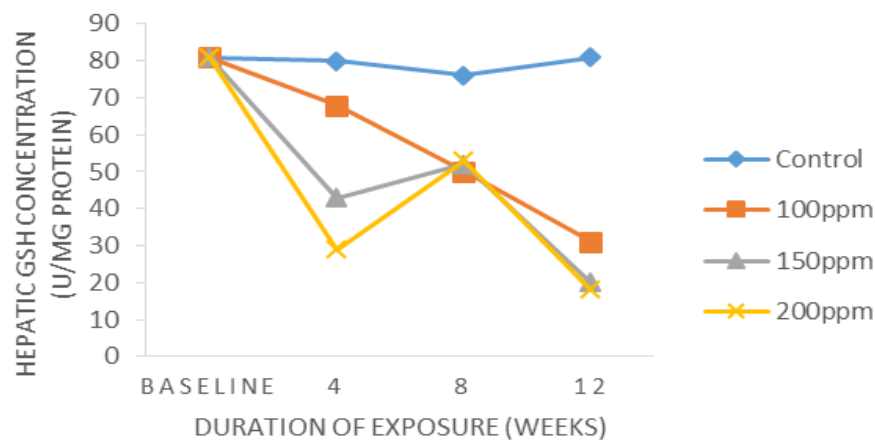

Fig. 4: Hepatic GSH concentration in rats exposed to different doses of inorganic arsenic.

As illustrated in fig. 4, exposure to the three doses of sodium arsenate for 4, 8 and 12 weeks significantly $(p<0.05)$ depleted hepatic GSH concentration at all doses and time interval. This depletion, which is dose dependent at four weeks is of magnitude 15, 46 and 64\% respective for 100, 150 and $200 \mathrm{ppm}$. Similarly, this observed depletion in hepatic GSH concentration is also dose dependent at 12 weeks. At 12 weeks $100 \mathrm{ppm}$ of the arsenicals reduced the GSH concentration in the liver by $62 \%$, while 150 and 200 ppm caused 75 and $78 \%$ reduction in the hepatic GSH concentration.

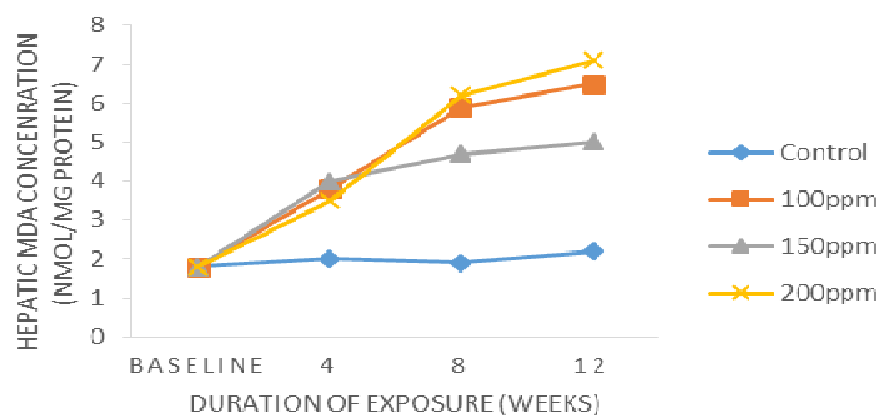

Fig. 5: Hepatic MDA concentration in rats exposed to different doses of inorganic arsenic.

On exposure to sodium arsenate for 4, 8 and 12 weeks, (Fig. 5), a significant increase in hepatic MDA concentration characterized the observed effects. This observed elevation of product of lipid peroxidation, though not dose - dependent was time - dependent at all doses. At all dosage level, the least significant increase in hepatic MDA level was at 4 weeks, while exposure for 12 weeks induced the most significant increase when compared with the baseline data.

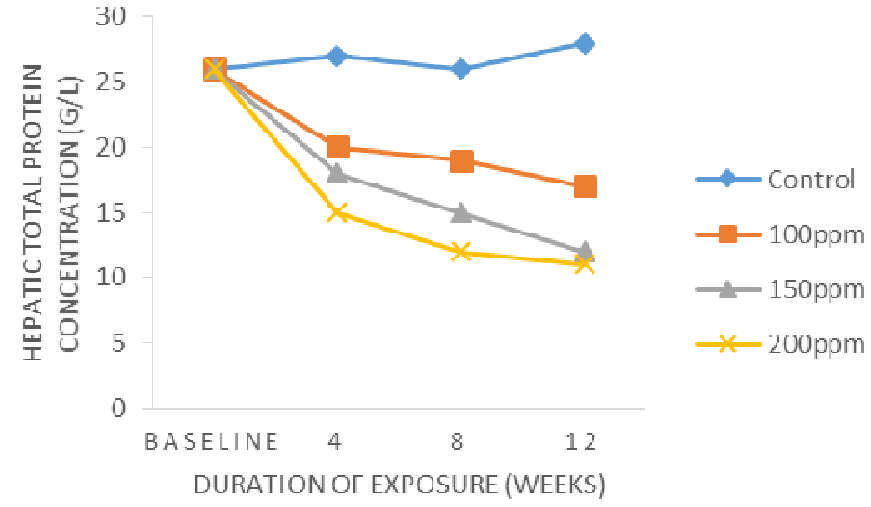

Fig. 6: Hepatic total protein concentration in rats exposed to different doses of inorganic arsenic. 
Figure 6 depicts the hepatic total protein concentration of arsenic - exposed animals. The arsenic compound at all dosage level and time interval induced a dose - and time - dependent decrease in hepatic total protein concentration. For instance, exposure to $100 \mathrm{ppm}$ sodium arsenate for 4 weeks reduced the hepatic total level by $26 \%$, while exposure to $200 \mathrm{ppm}$ of the same arsenate for 12 weeks reduced hepatic protein content by $61 \%$.

\section{Immuno - histochemical Staining.}

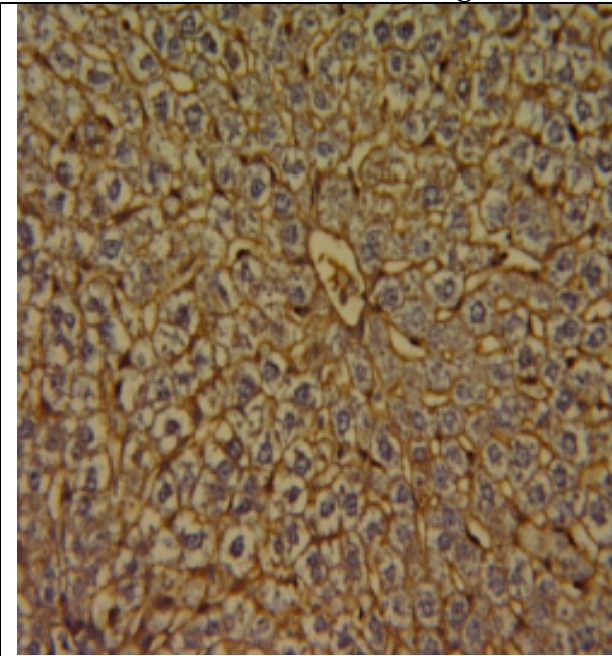

\section{Control}

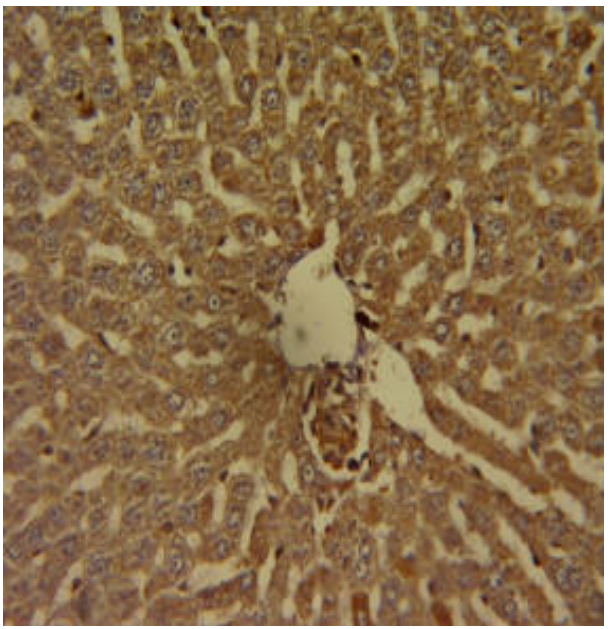

150 ppm sodium arsenate

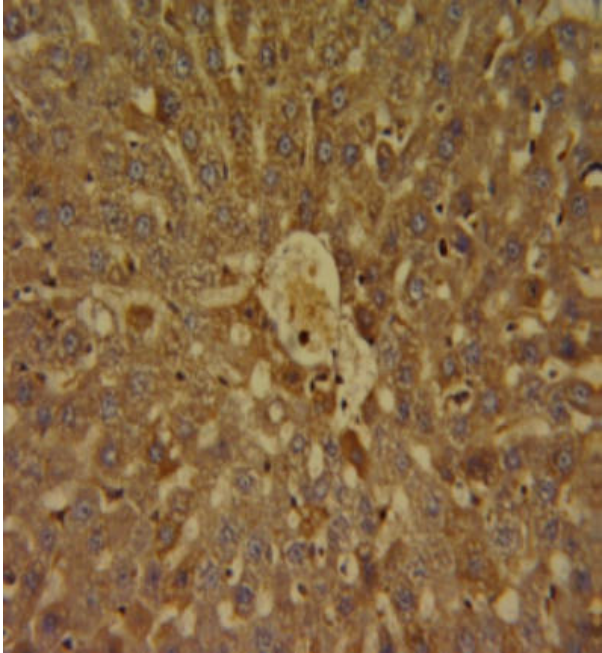

100 ppm sodium arsenate

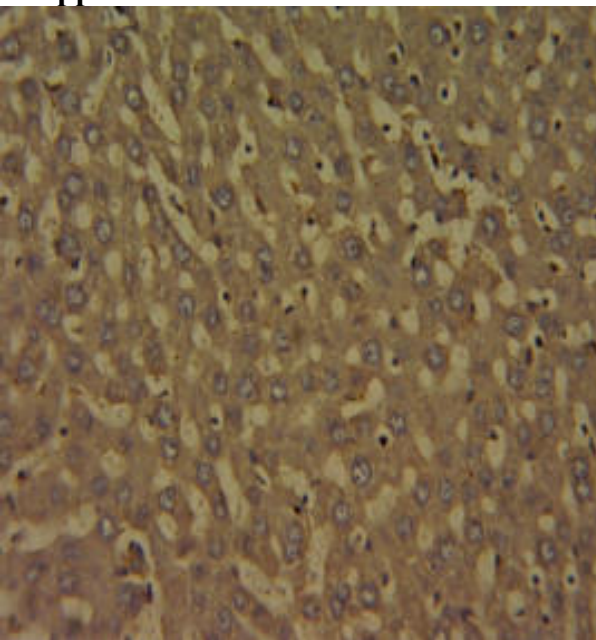

200 ppm sodium arsenate

Fig. 7; Expression of p53 in the liver of rats exposed to sodium arsenate for 4 weeks. Relative to the control groups, the arsenical down - regulated the expression of pro - apoptotic protein p53. Immunohistochemistry of the proteins revealed the presence of sparse protein staining in the hepatic gel of the animals exposed to sodium arsenate. In contrast, intense protein staining bserved in the control groups. 


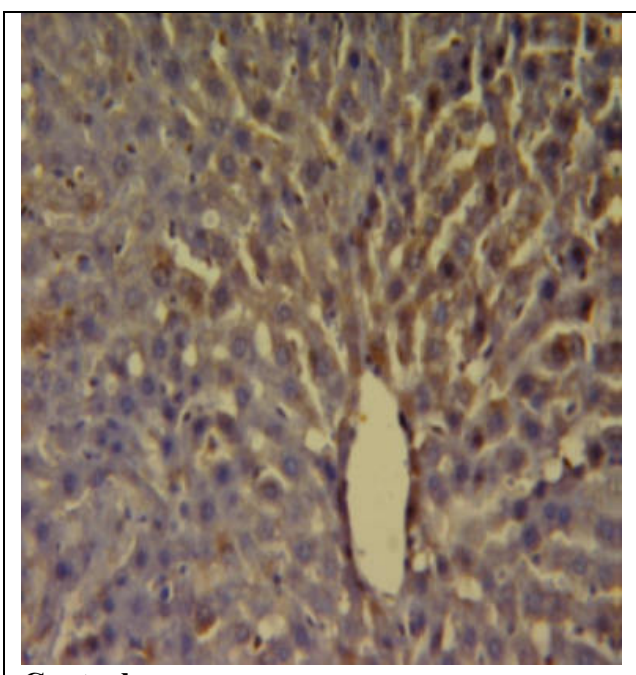

\section{Control}

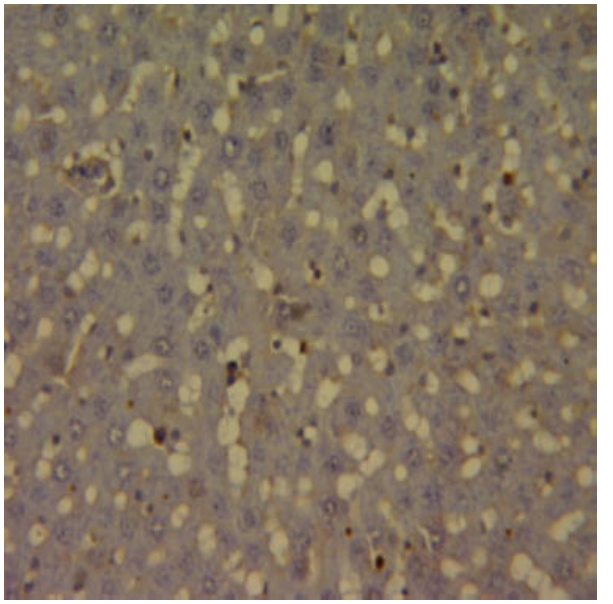

$150 \mathrm{ppm}$ sodium arsenate

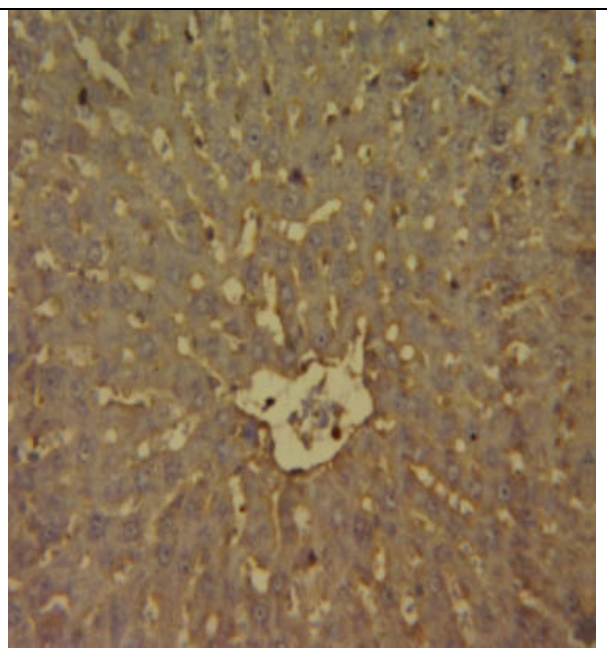

$100 \mathrm{ppm}$ sodium arsenate

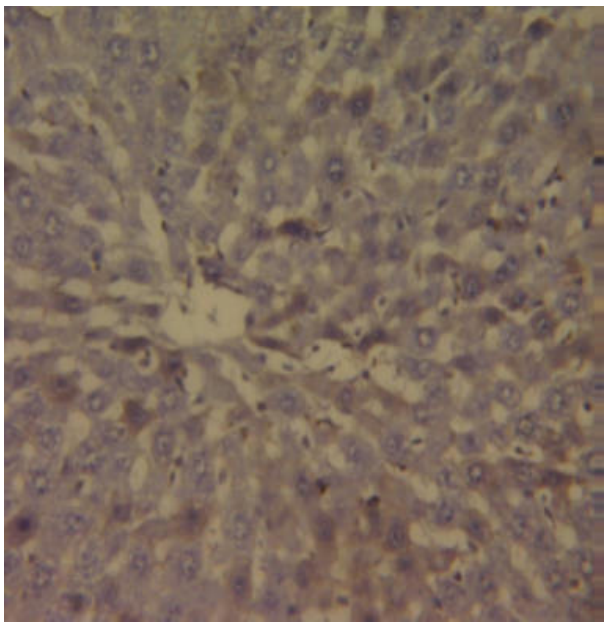

200 ppm sodium arsenate

Fig. 8; Expression of p53 in the liver of rats exposed to sodium arsenate for 8 weeks. Relative to the control groups, the arsenical down - regulated the expression of pro - apoptotic protein p53. Immunohistochemistry of the proteins revealed the presence of sparse protein staining in the hepatic gel of the animals exposed to sodium arsenate. In contrast, intense protein staining was observed in the control groups. 


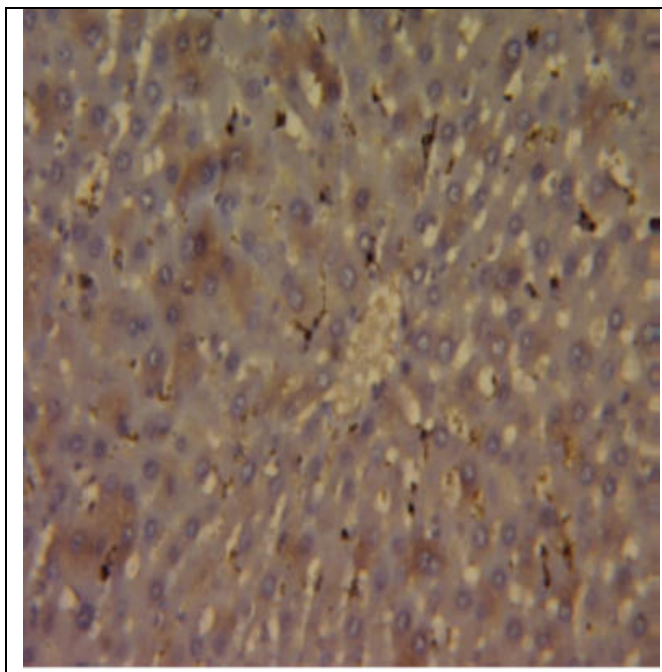

\section{Control}

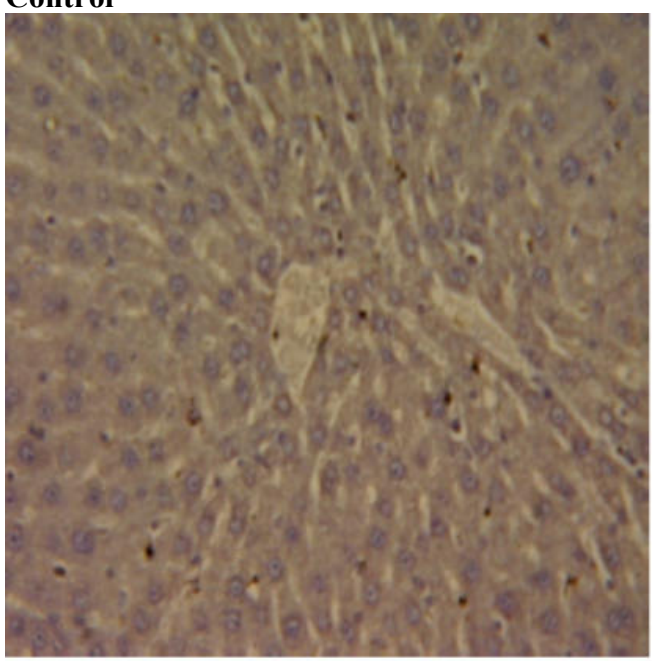

150 ppm sodium arsenate

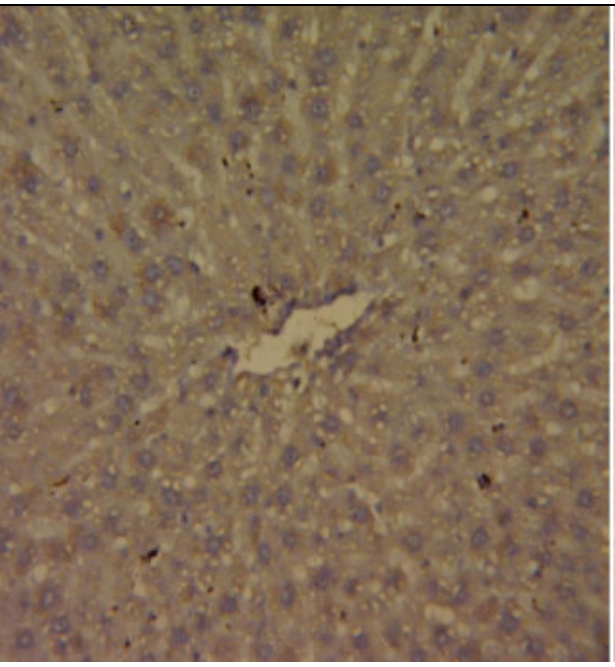

100 ppm sodium arsenate

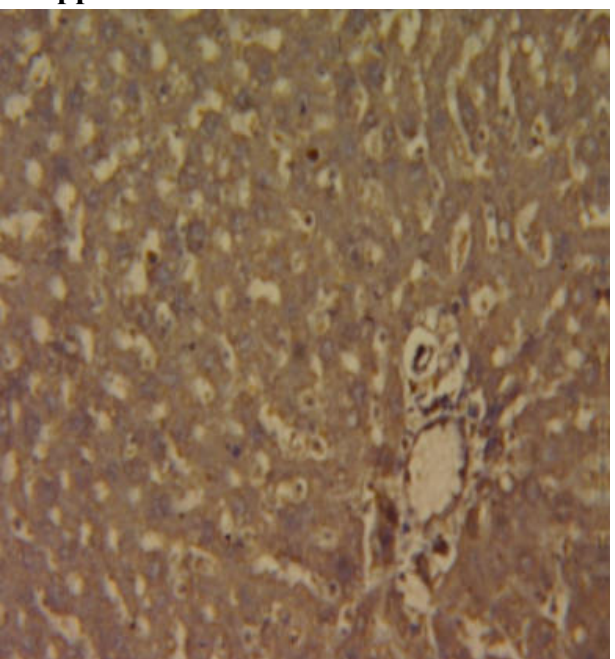

200 ppm sodium arsenate

Fig. 9; Expression of p53 in the liver of rats exposed to sodium arsenate for 12 weeks. Relative to the control groups, the arsenical down - regulated the expression of pro - apoptotic protein p53. Immunohistochemistry of the proteins revealed the presence of sparse protein staining in the hepatic gel of the animals exposed to sodium arsenate. In contrast, intense protein staining was observed in the control groups.

\section{Discussion}

Several past studies have reported the very crucial roles of endogenous antioxidants in the effective mechanism of preventing free radicals - induced tissue damage (Elasoru et al., 2018). Examples of such endogenous antioxidants include SOD, Catalase, GPx and GSH. SOD is involved in the immediate transformation of superoxide anion $\left(\mathrm{O}_{2}^{-}\right)$to hydrogen peroxide $\left(\mathrm{H}_{2} \mathrm{O}_{2}\right)$. This process becomes very important in order to prevent $\mathrm{O}_{2}{ }^{-}$from participating in the reaction that leads to the formation of extremely pernicious hydroxyl radicals. The $\mathrm{H}_{2} \mathrm{O}_{2}$ is also a very potent oxidants and needs to be eliminated as fast as possible. The removal of $\mathrm{H}_{2} \mathrm{O}_{2}$ can be achieved by the activity of either catalase or GPx. Either of the two enzymatic antioxidants catalyzes the conversion of $\mathrm{H}_{2} \mathrm{O}_{2}$ to water $\left(\mathrm{H}_{2} \mathrm{O}\right)$. GSH in its own case functions as a source of electrons for GPx to reduce $\mathrm{H}_{2} \mathrm{O}_{2}$ to $\mathrm{H}_{2} \mathrm{O}$ (Peltola et al., 1992; Zini \& Schlegel, 1996; Vaisberg et al., 2005). As shown in figs 1, 2, 3, and 4, the different doses (100 ppm, $150 \mathrm{ppm}$ and $200 \mathrm{ppm}$ ) of inorganic arsenate for 4, 8 and 12 weeks resulted in a significant reduction in the activities of SOD, catalase and GPx as well as in the concentration of GSH in the liver. The reduction in the activity of SOD was time - and dose - dependent (Fig. 1). Meanwhile in the case of catalase, the decrement in the enzymic activity is most significant at 8 weeks (Fig. 2). The down - regulation of GPx activity by the arsenic species was also dose - dependent in each time interval (Fig. 3), and the most significant reduction in the activity was observed at 12 weeks. Similarly, the most significant effect of the arsenic specie on the concentration of GSH was by $200 \mathrm{ppm}$ at 12 weeks (Fig. 4). The decrement in these 
endogenous antioxidants observed in this study suggest an inorganic arsenic - induced swift depletion of stored antioxidants enzymes and protein. In view of this, it may be suggested that one of the major mechanisms through which inorganic arsenic induces its toxicity is through excessive generation of free radicals and therefore depletion of endogenous antioxidants. The above observation is in total agreement with the submissions of Hughes (2002); Pi et al. (2002); Kitchin and Ahmad (2003) who proposed that arsenic exert its toxicity chiefly by induction of free radicals formation.

Lipid peroxidation is an accumulated effect of upsurge of free radicals production and failure of both the enzymatic and non - enzymatic antioxidants to either prevent the formation or scavenge the already formed free radicals. As a result of this, fatty acids in the cell are readily oxidized by reactive oxygen species (ROS) leading to the production of lipid peroxyl radicals. The lipid peroxyl radicals are then subsequently transformed into lipid peroxides in form of malondialdehyde (MDA) (Rao et al., 2001; Badmus et al., 2013). Initiation of lipid peroxidation may be by reactive oxygen species (ROS) with its ability to remove allylic hydrogen atom from a methylene group of polyunsaturated fatty acid side chains (Badmus et al., 2011). In the present study, as shown in fig. 5, significant elevation of MDA which is an end product of lipid peroxidation characterized the effects of exposure to inorganic arsenate at all doses and time intervals. This finding corroborates the reduced activities of SOD, catalase and GPx, as well as reduced GSH concentration observed in this study following exposure to the various dose regimens of inorganic arsenic. The observed increase in MDA concentration in the liver of the exposed animals is an indication of lipid peroxidation in the rats. This peroxidation process has been implicated in excessive damage, decrease membrane fluidity and exacerbation of the activities of various enzymes all of which are associated with degenerative disease, cancer, inflammation and ageing (Ames et al., 1993; Finkel et al., 2000; Elasoru et al., 2018).

Fig. 6 depicts the hepatic total protein concentration. The figure indicates that all the three doses of arsenic significantly reduced the total protein concentration in the liver of the exposed animals when compared with the control animals. This reduction in hepatic protein concentration is time - and dose - dependent. Rooyackers et al. (1996) and Balagopal et al. (1997) have previously observed higher burden of free radicals causing imbalance in homeostatic phenomena between systemic oxidants and antioxidants in the down - regulation of muscle and mitochondria protein synthetic process, thus leading to decline in total cellular protein as observed in this study. This observation is consistent with the earlier findings in this study that the mechanism through which arsenic induces its toxic effects might be through excessive generation of free radicals, as well as, reducing the levels of antioxidant enzymes and proteins. Therefore, the finding from this study is suggestive of the fact that the lower hepatic total protein observed in this study is as a result of arsenic induced - oxidative stress, which previous studies have reported (Kataria et al., 1991; Welle et al., 1994; Ogundu et al., 2013).

The oncoprotein p53 is a tumor suppressor protein and a phosphoprotein encoded by p53 gene (Megha et al., 2002). It functions as the "guardian of the genome" as it monitors the integrity of DNA during cell cycle by blocking the progression of cell with damaged or altered DNA to G1 phase of the cell cycle, giving room for genome repairing system. In a normal cell, the wild - type p53 present as an inactive latent form (Levine, 1997) is mainly expressed at moderate levels. This low basal level is usually maintained during cell cycle progression (Blagosklonny, 2002). However, during cellular or genotoxic stress, such as DNA damage, there is nuclear activation of the wild-type p53 gene (Volgelstein et al., 2000). Failure of the repairing system will make p53 to induce the expression of $\mathrm{p} 21$ protein which will in turn make the cell to die apoptotically. In this study, the under - expression of cytoplasmic p53 in all the treated groups relative to control groups, indicates that exposure to $100 \mathrm{ppm}, 150 \mathrm{ppm}$ and $200 \mathrm{ppm}$ inorganic arsenic even as early as at 4 weeks may significantly lower the physiologic p53-mediated apoptosis. In a study by Adeleke and Adaramoye (2017), using a different environmental toxicants, oxidative stress and down - regulation of p53 were both implicated in hepatotoxicity of experimental rats.

On the basis of our findings, induction of oxidative stress and down - regulation of p53 protein expression could be an important mechanisms underlying inorganic arsenic - induced hepatotoxicity in rats.

\section{References}

Adeleke, G. E. \& Adaramoye, O. A. (2017). "Modulatory role of betulinic acid in N-nitrosodimethylamineinduced hepatorenal toxicity in male Wistar rats", Hum Exp Toxicol, 36(7), 734-43.

Ames, B. N., Shigenaga, M. K. \& Hagen, T. M. (1993). "Oxidants, antioxidants and the degenerive diseases of aging”, Proc Natl Acad Sci, 90, 7915-7922.

Arthur, J. R. (1985). "Superoxide dismutase and glutathione peroxidase activities in neutrophils from selenium deficient and copper deficient cattle”, Life Sci, 36(16), 1569-1575.

Badmus, J. A., Adedosu, O. T., Fatoki, J. O., Adegbite, V. A., Adaramoye, O. A. \& Odunola, O. A. (2011). "Lipid peroxidation inhibition and antiradical activities of some fractions of Mangifera indica", Acta Poloniae Pharmaceutica - Drug Research, 68(1), 23-29.

Badmus, J. A., Odunola, O. A., Yekeen, T. A., Gbadegesin, A. M., Fatoki, J. O., Godo, M. O., Oyebanjo, K. S. 
\& Hiss, D. C. (2013). "Evaluation of antioxidant, antimutamutagenic, and lipid peroxidation inhibitory activities of selected fractions of holarrhena floribunda (G. Don) leaves", Acta Biochim Pol, 60(3), 435-42.

Balagopal, P., Rooyackers, O. E., Adey, D. B., Adex, P.A. \& Nair, K. S. (1997). "Eff.ects of aging on in vivo synthesis of skeletal muscle myosin heavy-chain and sarcoplasmic protein in humans", Am $J$ Physiol, 273(36), 790-800.

Beutler, E., Dubon, O. B. \& Kelly, M. (1963). "Improved method for the determination of blood glutathione", $J$ Lab Clin Med, 61, 882-888.

Blagosklonny, M. V. (2002). "p53: an ubiquitous target of anticancer drugs", Int. J. Cancer, 98, 161-66.

Butt, A. S. \& Rehman, A. (2011). "Isolation of arsenite-oxidizing bacteria from industrial effluents and their potential use in wastewater treatment", World J. Microbiol. Biotechnol, 27(10), 2435-41.

Chakravarthi, S., Long, A. S., Hannien, B., Pasupati, T., Palayan, K. \& Talib A. (2010). "The expression of p53 as a reliable immunohistochemical marker for clinicopathological correlation of gastric adenocarcinomas", Res J Med Sci, 4(1), 15-19.

Demirovic, A., Ulamec, M., Bezjak, M., Belicza, M. \& Kruslin, B. (2014), “Apoptotic markers (p53, Bcl-2 and Bax) expression in renal oncocytoma and chromophobe renal cell carcinoma", Periodicum Biologorum, 116 (2), 173-176.

Elasoru, S.E., Adedosu, O. T., Fatoki, J. O. \& Kehinde, B. D. (2018). "Falavonoid-rich extracts of Solanum macrocarpon leaves shows tissue protective and ameliorate certain inflammatory and oxidative indices associated wiyh D-galactose exposed rats", World Journal of Pharmacy and pharmaceutical Sciences, 7(2), 278-302.

Feridooni, T., Hotchkiss, A., Remley-Carr, S., Saga, Y. \& Pasumarthi, K. B. (2011), "Cardiomyocyte specific ablation of p53 is not sufficient to block doxorubicin induced cardiac fibrosis and associated cytoskeletal changes", PLoS One, 6, e22801.

Finkel, T. \& Holbrook, N. J. (2000). "Oxidants, oxidative stress and the biology of ageing”, Nature, 408(6809), $239-47$

Finsterer, J. \& Ohnsorge, P. (2013). "Influence of mitochondrion-toxic agents on the cardiovascular system", Regul. Toxicol.Pharmacol, 67, 434-45.

Flora, S. J. S., Bhadauria, S., Kannan, G. M. \& Singh, N. (2007), “Arsenic induced oxidative stress and the role of antioxidant supplementation during chelation: A review”, Journal of Environmental Biology, 28 (2), 333 347.

Gebel, T. (2000) "Confounding variables in the environmental toxicology of arsenic", Toxicology, 144, $155-62$.

Ghosh, S., Dungdung, S. R. \& Chowdhury, S. T., Mandal, A. K., Sarkar, S., Ghosh, D. \& das, N. (2011). "Encapsulation of the flavonoid quercetin with an arsenic chelator into nanocapsules enables the simultaneous delivery of hydrophobic and hydrophilic drugs with a synergistic effect against chronic arsenic accumulation and oxidative stress," Free Radical Biology and Medicine, 51 (10), 1893-1902.

Gornall, A. G., Bardwill, C. J. \& David, M. M. (1949). "Determination of serum protein by means of Biuret reaction", J Biol Chem, 177, 751-766.

Hughes, M. F. (2002). “Arsenic toxicity and potential mechanism of action”, Toxicology Letters, 133, 1-16.

Kataria, N., Sareen, M., Kataria, A. K., Bhatia, J. S. \& Ghosal, A. K. (1991). "Some observations on total serum proteins in camels", Indian Vet Med J, 15, 38-43.

Kitchin, K. T. \& Ahmad, S. (2003). "Oxidative stress as a possible mode of action for arsenic carcinogenesis" Toxicology Letters, 137(1-2), 3-13.

Klaassen, C. D. (1996) "Heavy metals and heavy metal antagonist", In: Gilman, A. G., Rall, T. W., Nies, A. S. et al. ed. The Pharmacological Basis of Therapeutics. 9th ed. New York, NY: McGraw Hill, pp1592-614.

Levine, A. J. (1997) "p53, the cellular gatekeeper for growth and division”, Cell, 88, 323-31.

Ma, S., Zhang, H., Sun, W., Gong, H., Wang, Y., Ma, C., Wang, J., Cao, C., Yang, X., Tian, J. \& Jiang, Y. (2013), "Hyperhomocysteinemia induces cardiac injury by up-regulation of p53-dependent Noxa and Bax expression through the p53 DNA methylation in $\mathrm{APOE}^{-/-}$mice", Acta Biochim Biophys Sin, 45 (5), 391 400.

Mateos, L. M., Ordóñez, E., Letek, M. \& Gil, J. A. (2010). "Corynebacterium glutamicum as a model bacterium for the bioremediation of arsenic", Int. Microbiol 9(3), 207-15.

Matschullat, J. (2000). "Arsenic in the geosphere-a review", The Science of the Total Environment, 249, 297312.

Megha, T., Ferrari, F., Benvenuto, A., Bellan, C. Lalinga, A. V., Lazzi, S., Bartolommei, S., Cevenini, G., Leoncini, L. \& Tosi, P. (2002). "p53 mutation in breast cancer. Correlation with cell kinetics and cell of origin", J Clin Pathol, 55(6), 461-6.

Moskovitz, J., Yim, M. B., \& Chock, P. B. (2002). "Free radicals and disease", Arch. Biochem. Biophys, 397, 354-59.

Obinaju, B. E. (2009). "Mechanisms of arsenic toxicity and carcinogenesis”, Afr. J. Biochem. Res 3(5), 232-37. 
Ogundu, U. E., Okoro. V. M. O., Okeke, G. U., Durugo, N., Mbaebie, G. A. C. \& Ezebuike, C. I. (2013). "Effects of age, breed and sex on the serum biochemical values of Turkeys (Meleagridis gallopova) in South-eastern Nigeria", Afr J Agric Res, 8(23), 2825-2828.

Pace, C., Dagda, R. \& Angermann, J. (2017). “Antioxidants Protects against Arsenic Induced Mitochondrial Cardio-Toxicity", Toxics, 5(38), 1-41.

Peltola, V., Huhtaniemi, I. \& Ahotupa, M. (1992). “Antioxidant enzyme activity in the maturing rat testis”, $J$ Androl, 13(5), 450-5

Pi, J., Yamauchi, H., Kumagai, Y., Sun, G., Yoshida, T., Aikawa, H., Hopenchayn-Rich, C. \& Shimojo, N. (2002). "Evidence for induction of oxidative stress caused by chronic exposure of Chinese residents to arsenic contained in drinking water." Environmental Health Perspectives, 110, 331-336.

Rao, C. V., Hirose, Y., Indranie, C. \& reddy, B. S. (2001) "Modulation of experimental colon tumorigenesis by types and amounts of dietary fatty acids", Cancer Res, 61, 1927-1933

Ratnaike, R. N. \& Barbour, A. H. (2000). "Maldigestion and malabsorption", In: Ratnaike, R. N. ed. Small bowel disorders. London: Edward Arnold, pp302.

Ratnaike, R. N. (2003). “Acute and chronic arsenic toxicity”, Postgrad Med J 79, 391-96.

Rolland, P., Spendlove, I., Madjid, Z., Rakha., E. A., Patel, P., Ellis, I. O. \& Durrant, L. (2007), The p53 positive Bcl-2 negative phenotype is an independent marker of prognosis in breast cancer. Int. J. Cancer, 120, 13111317.

Rooyackers, O. E., Adey, D. B., Ades, P. A. \& Nair, S. K. (1996). "Effect of age on in vivo rates of mitochondrial protein synthesis in human skeletal muscle", Proc Natl Acad Sci USA, 93, 15364-15369.

Rotruck, J. T., Pope, A. L., Ganther, H. E., Swanson, A. B., Hafeman, D. G. \& Hoekstra, W. G. ( 1957). "Selenium: Biochemical role as a component of glutathione peroxidase", Science, 179(4073), 588-590.

Satyapal, G. K., Mishra, S. K., Srivastava, A., Ranjan, R. K., Prakash, K., Haque, R. \& Kumar, N. (2018), "Possible bioremediation of arsenic toxicity by isolating indigenous bacteria from the middle Gangetic plain of Bihar, India", Biotechnology Reports 17, 117-125.

Sinha, A. K. (1972). "Colorimetric Assay of Catalase”, Analytical Biochemistry, 47(2), 389-394.

Vaisberg, C. N., Jelazarsky, L. V., Dishlianova, B. \& Chaushev, T. A. (2005). "Activity, substrate detection and immunolocalization of glutathione peroxidase (GPx) in bovine reproductive organs and semen", Theriogenology, 64(2), 416-28.

Varshney, R. \& Kale, R. K. (1990). "Effects of Calmodulin Antagonist on Radiation Induced Lipid Peroxidation in Microsomes", Int J Radiat Biol, 58, 33-743.

Volgelstein, B., Lane, D. \& Levine, A. J. (2000). "Surfing the p53 network" Nature, 408, 307-10.

Welle, S., Thornton, C., Statt, M. \& McHenry, B. (1994). "Postprandial myofibrillar and whole body protein synthesis in young and old human subjects", Am J Physiol, 267(30), 599-604.

Zaw, M. \& Emett, M. T. (2002). "Arsenic removal from water using advanced oxidation processes", Toxicol Lett, 133, 113-18

Zhang, Z., Gao, L., Cheng, Y., Jiang, J., Chen, Y., Jiang, H., Yu, H., Shan, A. \& Cheng, B. (2014), "Resveratrol, a Natural antioxidants, has a Protective Effect on Liver Injury Induced by Inorganic Arsenic Exposure", BioMed research International, 2014, 1-7.

Zini, A. \& Schlegel, P. N. (1996). "Catalase mRNA in the male rat reproductive track", Journal of Andrology, 17(5), 473-80. 